[6] Osadchiy S.I. Kombinirovannyiy metod sinteza optimalnyih sistem stabilizatsii mnogomernyih podvizhnyih ob'ektov pri statsionarnyih sluchaynyih vozdeystviyah / S.I. Osadchiy, V.A. Zozulya. // Mezhdunarodnyiy nauchnotehnicheskiy zhurnal «Problemyi upravleniya i informatiki». - 2013. - \#3. - S. 40-49.;

[7] Azarskov V.N. Metodologiya konstruirovaniya optimalnyih sistem stohasticheskoy stabilizatsii: Monografiya / V.N. Azarskov, L.N. Blohin, L.S. Zhitetskiy / Pod red. Blohina L.N. - K.: Knizhnoe izdatelstvo NAU, 2006. - 440s.;

[8] Davis M.C. Factoring the spectral matrix/ M.C.Davis // IEEE Trans. Automat. Cointr. - 1963.- AC-8, N 4. - p. 296305 ;

[9] Kwakernaak H. Polynomial J-Spectral Factorization / H. Kwakernaak, M. Sebek // IEEE Transactions On Automatic Control - 1994 - VOL.39 - NO. 2 - pp. 315-328;

[10]Gantmaher F.R. Teoriya matrits/ F.R.Gantmaher -4-e izd.- M.: Nauka, 1988.- 552s.

\title{
ИССЛЕДОВАНИЕ ЭНЕРГЕТИЧЕСКИХ ХАРАКТРЕИСТИК КОГЕНЕРАЦИОННОЙ ЭНЕРГЕТИЧЕСКОЙ УСТАНОВКИ В УСЛОВИЯХ ИЗМЕНЕНИЯ КАЧЕСТВА ТОПЛИВА
}

The research of the energy characteristics of cogeneration power plant in a changing fuel quality

к.т.н., зав. лаб., Тарахтий О.С. (Tarakhtii O.S.), Бундюк А.Н. (Bundiuk A.N.), к.т.н., профессор

Одесский национальный политехнический университет, Одесса, E-mail: larionova-olya@ mail.ru

Copyright (C) 2014 by author and the journal “Automation technological and business - processes".

This work is licensed under the Creative Commons Attribution International License (CC BY).

http://creativecommons.org/licenses/by/4.0/

\section{Аннотация}

Из-за несовершенства технологических производств многие промышленные предприятия имеют побочные газообразные продукты, которые относятся к вторичным энергоресурсам. Использование таких газов в качестве топлива для энергетических установок данных предприятий является актуальной задачей энергосбережения. В данной статье рассматривается возможность использования технологических газов и газов искусственного происхождения в качестве топлива для когенерационной энергетической установки на базе газотурбинного двигателя. Использование данных видов топлива в когенерационны энергетических установках позволит снизить стоимость выпускаемой продукции за счет снижения затрат на топливо. Однако использование подобных газов в качестве основного топлива для энергоустановок

осложняется тем, что низшая теплота сгорания таких газов может существенно изменяться и, таким образом вносить существенные возмущения в работу энергетических установок. Проведен анализ влияния изменения низшей теплоты сгорания рассматриваемых газов на энергетические характеристики теплового двигателя когенерационной энергетической установки и определены допустимые пределы изменения низшей теплоты сгорания топлива. Предложены структура системы автоматического регулирования и метод управления мощностью газотурбинной установки за счет перераспределения потоков первичного и вторичного воздуха в камере сгорания. В контур регулирования температуры газов на выходе из камеры сгорания газотурбинной $\backslash$ 
установки введен дополнительный сигнал по производной от температуры газов на выходе из камеры сгорания. Использование этого сигнала значительно повышает качество регулирования нагрузки газовой турбины, особенно при снижении низшей теплоты сгорания топлива.

\begin{abstract}
Due to the imperfection of technological production, many industrial enterprises have gaseous side products, which are secondary energy resources. The use of such gases as fuel for power plants of these companies is an important task of energy saving. This article discusses the use of process gases and gases of artificial origin as a fuel for cogeneration power plants based on gas turbine engine. The use of fuels in cogeneration power plants will reduce the cost of production by reducing fuel costs. However, the use of such gas as the primary fuel for power plants is complicated by the fact that the lowest heat of combustion of these gases can vary significantly and thus introduce considerable disturbances in the operation of power plants. The analysis of influence of change of net calorific value of the considered gases on the energy characteristics of the heat engine cogeneration power plant and defines the acceptable limits of change of net calorific value of fuel. The structure of the automatic control system and control method of power gas-turbine installations due to the flow distribution of primary and secondary air in the

combustion chamber. In the circuit controlling the temperature of the gases at the outlet from the combustion chamber of the gas turbine installation input signal derived from the temperature of the gases at the outlet from the combustion chamber. The use of this signal greatly improves the quality of control of the load of the gas turbine, particularly at lower net calorific value of fuel.
\end{abstract}

Ключевые слова

Когенерационная энергетическая установка, несертифицированные виды топлива, энергетические характеристики, изменение низшей теплоты сгорания топлива

Keywords

Cogeneration power plant, non-certified fuel types, energy characteristics, change of net calorific value of fuel

\title{
Введение
}

Из-за энергетического несовершенства технологических производств многие промышленные предприятия имеют побочные газообразные продукты технологических процессов, являющиеся вторичными энергоресурсами (ВЭР). Основная задача повышения эффективности теплотехнических производств состоит в наиболее полном использовании ВЭР, в том числе в качестве энергетического или технологического топлива [1-3]. Например, на предприятиях нефтеперерабатывающей и металлургической промышленности существуют нерегулярные излишки собственных несертифицированных газов, образующиеся при переработке сырья, которые не эффективно утилизируются [3].

Использование несертифицированных газов, а также газов искусственного происхождения, в качестве топлива для энергетических установок, позволяет снизить расход природного газа, и как следствие, уменьшить стоимость выпускаемой продукции [4,5].

Однако использование таких газов в качестве основного топлива осложняется тем, что низшая теплота сгорания этих газов может значительно изменяться и, таким образом, вносить возмущения в режим работы энергетических установок, в частности когенерационных энергетических установок (КЭУ) [5].

Постановка задачи

Исследовать изменения энергетических характеристик когенерационной энергетической установки, при использовании несертифицированных видов топлива.

Изложение основного материала

С целью проведения анализа изменения энергетических характеристик когенерационной установки были выбраны несертифицированные газы следующего состава, представленные в таблице 1. 


\section{МЕТОДИ ТА АЛГОРИТМИ ЕФЕКТИВНОГО УПРАВЛІННЯ ОБ‘ЭКТАМИ}

Таблица 1. Характеристики несертифицированных газов

\begin{tabular}{|c|c|c|c|c|c|c|c|c|c|c|c|c|c|}
\hline \multirow[b]{2}{*}{$\begin{array}{c}\text { Газообразное } \\
\text { топливо }\end{array}$} & \multicolumn{11}{|c|}{ Состав газов, \% по объему } & \multirow[b]{2}{*}{ 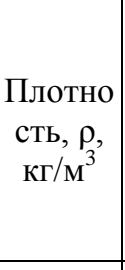 } & \multirow{2}{*}{$\begin{array}{c}\text { Теплота } \\
\text { сгорани } \\
\text { я } \\
\text { низшая, } \\
Q_{\mathrm{H}}^{\mathrm{p}}, \\
\text { кДж/кг }\end{array}$} \\
\hline & $\begin{array}{l}\text { Мета } \\
\text { н } \mathrm{CH}_{4}\end{array}$ & $\begin{array}{l}\text { Этан } \\
\mathrm{C}_{2} \mathrm{H}_{6}\end{array}$ & $\begin{array}{c}\text { Пропан } \\
\mathrm{C}_{3} H_{8}\end{array}$ & $\begin{array}{l}\text { Бутан } \\
C_{4} H_{10}\end{array}$ & $\mid \begin{array}{c}\text { Пентан } \\
\mathrm{C}_{5} H_{12}\end{array}$ & $\begin{array}{c}\text { Гексан } \\
\mathrm{C}_{6} H_{12}\end{array}$ & $\begin{array}{c}\text { Азот } \\
\mathrm{N}_{2}\end{array}$ & $\begin{array}{c}\text { Водор } \\
\text { од } H_{2}\end{array}$ & $\begin{array}{c}\text { Моноокс } \\
\text { ид } \\
\text { углерода } \\
C O\end{array}$ & $\begin{array}{c}\text { Двуокис } \\
\text { ь } \\
\text { углерода } \\
\mathrm{CO}_{2}\end{array}$ & $\begin{array}{c}\text { Кисл } \\
\text { ород } \\
\mathrm{O}_{2}\end{array}$ & & \\
\hline Природный газ & 88,35 & 5,26 & 2,29 & 0,52 & 0,09 & 0,05 & 1,96 & - & - & 1,48 & - & 0,782 & 45348 \\
\hline $\begin{array}{l}\text { Коксовый газ } \\
\text { из каменных } \\
\text { углей } \\
\end{array}$ & 25 & \multicolumn{5}{|c|}{2} & 4 & 58 & 7 & 3 & 0,2 & 0,800 & 22504 \\
\hline $\begin{array}{l}\text { Генераторный } \\
\text { газ } \\
\text { (парокислородн } \\
\text { ый) }\end{array}$ & 9,85 & \multicolumn{5}{|c|}{1,027} & 2,25 & 59,1 & 21,2 & 1,9 & 0,3 & 1,15 & 11941 \\
\hline $\begin{array}{ll}\text { Коксовый } & \text { газ } \\
\text { из сланцев } & \end{array}$ & 23,7 & \multicolumn{5}{|c|}{5,7} & 2 & 38,6 & 10,9 & 18,8 & 0,3 & 0,65 & 30918 \\
\hline $\begin{array}{l}\text { Генераторный } \\
\text { газ (водяной) }\end{array}$ & 0,5 & \multicolumn{5}{|c|}{-} & 6,4 & 48,0 & 38,5 & 6 & 0,2 & 0,7 & 14953 \\
\hline Шахтный метан & 68,6 & \multicolumn{5}{|c|}{2,6} & 10,7 & - & - & 10,6 & 0,5 & 0,72 & 40124 \\
\hline $\begin{array}{ll}\text { Газ при } \\
\text { перегонке } \\
\text { нефти } \\
\end{array}$ & 20,7 & 16,1 & 36,1 & 20,5 & 6,3 & - & - & 0,3 & - & - & - & 1,726 & 46528 \\
\hline Висбрекинг & 51,5 & 23,6 & 12,5 & 4,9 & 2 & - & - & 5,5 & - & - & - & 1,065 & 48069 \\
\hline Крекинг газ & 6,9 & 2,2 & 0,7 & 0,4 & 0,2 & - & - & 89,6 & - & - & - & 0,178 & 78322 \\
\hline
\end{tabular}

Из таблицы видно, что низшая теплота сгорания выбранных газов меняется в достаточно широком диапазоне: от 11941 кДж/кг до 78322 кДж/кг. Следовательно, можно предположить, что и температура газов на выходе камеры сгорания также будет существенно изменяться.

По данным таблицы были проведены тепловые расчеты первичного двигателя когенерационной установки (газотурбинная установка) для разных видов несертифицированных топлив, позволяющие оценить изменение энергетических характеристик работы установки. Результаты расчетов сведены в табл. 2.

Таблица 2. Результаты тепловых расчетов ГТУ

\begin{tabular}{|c|c|c|c|c|c|c|c|c|}
\hline $\begin{array}{c}\text { № } \\
\Pi / \Pi\end{array}$ & $\begin{array}{c}\text { Вид газообразного } \\
\text { топлива }\end{array}$ & $\begin{array}{l}\text { Плотност } \\
\text { ь } \rho, к \Gamma / \mathbf{M}^{3}\end{array}$ & $\begin{array}{c}\text { Низшая } \\
\text { теплота } \\
\text { сгорания, } \\
Q_{\mathrm{H}}^{\mathrm{p}}, \\
\text { кДж/кг }\end{array}$ & $\begin{array}{c}\text { Теоретически } \\
\text { необходимое кол- } \\
\text { во воздуха для } \\
\text { сжигания } 1 \text { кг } \\
\text { газа, } G_{\mathrm{B}}^{0}, \text { кг/кг }\end{array}$ & $\begin{array}{c}\text { Расход } \\
\text { воздуха } \\
\text { через } \\
\text { компрессор } \\
, G_{\text {в }}, \text { кг/c }\end{array}$ & $\begin{array}{c}\text { Расход } \\
\text { топлива, } \\
G_{\text {топ }}, \\
\text { кг/с }\end{array}$ & $\begin{array}{c}\text { Расход } \\
\text { газов } \\
\text { через } \\
\text { турбину, } \\
G_{\Gamma}, \text { кг/с }\end{array}$ & $\begin{array}{c}\text { Температу } \\
\text { ра газов } \\
\text { на выходе } \\
\mathrm{KC}, t_{3},{ }^{\circ} \mathrm{C}\end{array}$ \\
\hline 1. & $\begin{array}{l}\text { Генераторный } \\
\text { (парокислородный) }\end{array}$ & 1,150 & 11941 & 3,17 & 10,18 & 0,825 & 10,95 & 654,3 \\
\hline 2. & $\begin{array}{l}\text { Генераторный газ } \\
\text { (водяной) }\end{array}$ & 0,700 & 14953 & 3,68 & 10,58 & 0,663 & 11,19 & 703,5 \\
\hline 3. & $\begin{array}{lrr}\text { Коксовый газ } & \text { из } \\
\text { каменных углей } & \\
\end{array}$ & 0,800 & 22504 & 6,43 & 11,04 & 0,446 & 11,43 & 826,8 \\
\hline 4. & $\begin{array}{lcc}\begin{array}{l}\text { Коксовый } \\
\text { сланцев }\end{array} & \text { газ из } \\
\end{array}$ & 0,650 & 30918 & 7,97 & 11,35 & 0,326 & 11,62 & 964,3 \\
\hline 5. & Шахтный метан & 0,720 & 40124 & 11,74 & 11,48 & 0,252 & 11,68 & 1114,7 \\
\hline 6. & Природный газ & 0,782 & 45348 & 15,74 & 11,47 & 0,224 & 11,64 & 1200,0 \\
\hline 7. & $\begin{array}{l}\text { Газ при перегонке } \\
\text { нефти }\end{array}$ & 1,726 & 46528 & 15,61 & 11,51 & 0,218 & 11,68 & 1219,3 \\
\hline 8. & Висбрекинг & 1,065 & 48069 & 16,36 & 11,52 & 0,212 & 11,68 & 1244,4 \\
\hline 9. & Крекинг газ & 0,178 & 78322 & 24,22 & 11,75 & 0,130 & 11,82 & 1738,6 \\
\hline
\end{tabular}


Из результатов расчетов, представленных в таблице 2, видно, что с изменением низшей теплоты сгорания топлива изменяется и теоретически необходимое количество воздуха $G_{\text {в }}^{0}$ для сжигания газа (рис. 1 ), а это влечет за собой изменение расхода воздуха через компрессор и расхода топлива $G_{\text {топ }}$.

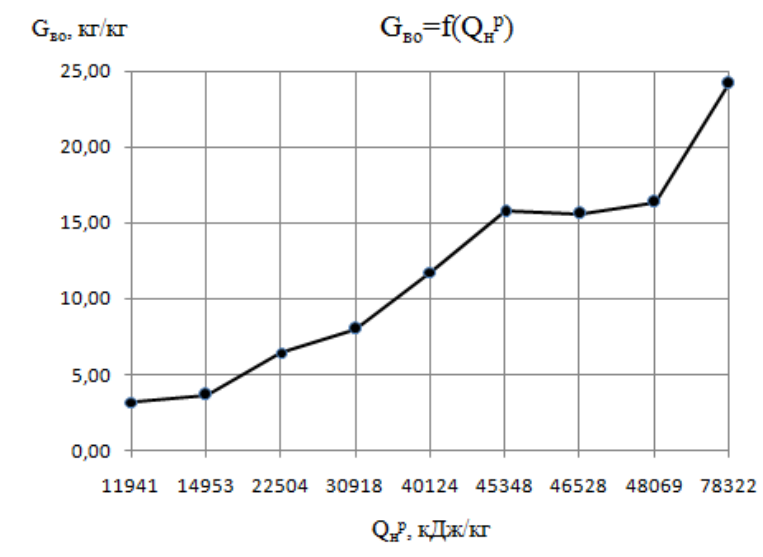

Рис. 1 - Изменение теоретически необходимого количества воздуха в зависимости от теплоты сгорания топлива

Также с изменением низшей теплоты сгорания топлива изменяется и температура газов на выходе камеры сгорания (КС) $t_{3}$ (рис. 2).

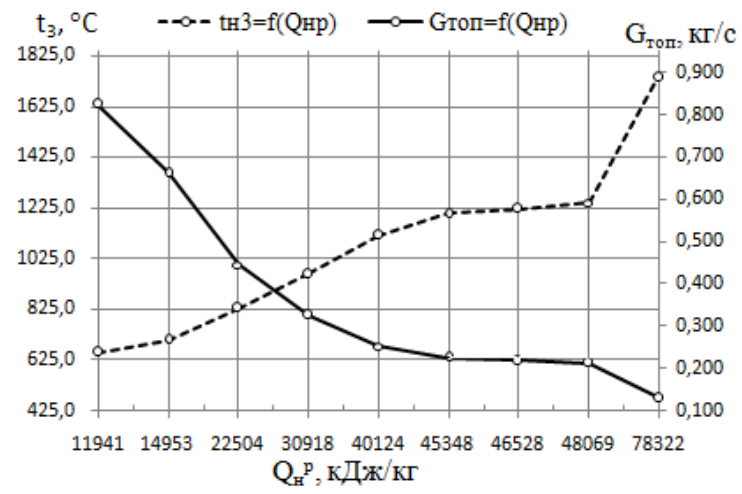

Рис. 2 - Изменение расхода топлива и температуры газов на выходе камеры сгорания

Снижение температуры газов на выходе из камеры сгорания влечет за собой снижение полезной работы газовой турбины, т.к. уменьшается работа расширения газов на валу турбины, а, следовательно, и КПД всей газотурбинной установки [6]. Повышение температуры газов выше расчетной $\left(1200{ }^{\circ} \mathrm{C}\right)$, вследствие увеличения теплотворной способности топлива, также недопустимо требованием жаропрочности материалов проточной части турбины.

Таким образом, при сжигании несертифицированных газов, для которых теплота сгорания имеет непостоянное значение, существует необходимость в регулировании температуры газов на выходе камеры сгорания.

С целью нейтрализации действия возмущения по изменению низшей теплоты сгорания топлива было принято решение в контур регулирования электрической нагрузкой генератора добавить сигнал по производной от изменения температуры газов на выходе из камеры сгорания. Такая коррекция системы автоматического управления позволила учитывать влияние изменения теплоты сгорания топлива еще до изменения частоты вращения ротора и таким образом снизить влияние этого возмущения [7].

Из таблицы 2 видно, что температура газов на выходе КС при снижении низшей теплоты сгорания топлива до 30918 кДж/кг и ниже существенно снижается, что является недопустимым с точки зрения регулирования мощности газотурбинной установки. Для цели регулирования температуры газов на выходе камеры сгорания при таких условиях предложено использовать перераспределение потоков первичного и вторичного воздуха в камере сгорания. Поток 
воздуха, идущий в камеру сгорания от компрессора равен сумме первичного воздуха $G_{\text {в1 }}$, поступающего в жаровую

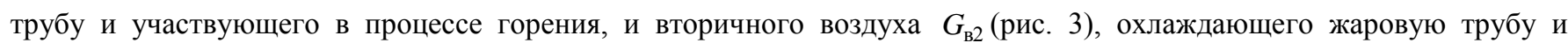
поступающего на выход камеры сгорания для охлаждения газов, выходящих из жаровой трубы: $G_{\mathrm{B}}=G_{\mathrm{B} 1}+G_{\mathrm{B} 2}$.

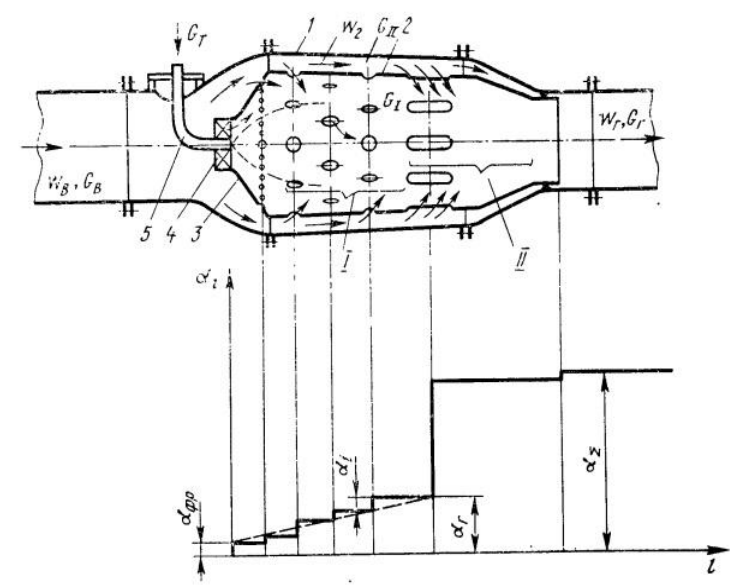

Рис. 3 - Схема воздушных потоков в камере сгорания

При увеличении теплотворной способности топлива, температура газов на выходе камеры сгорания возрастает. Для ее снижения следует уменьшить расход топлива в камеру сгорания. Таким образом, изменение низшей теплоты сгорания топлива в большую сторону от номинального значения, не вызывает трудностей при управлении когенерационной энергетической установкой. В случае же, уменьшения теплотворной способности топлива, температура газов на выходе камеры сгорания также снижается. В этом случае следует увеличивать расход топлива, поступающего в камеру сгорания.

Так как в камерах сгорания газотурбинных установок процесс горения протекает при большом коэффициенте избытка воздуха $(\alpha=3 \div 5)$ [8], увеличение расхода топлива в небольших пределах от номинального значения не потребует увеличения подачи воздуха. При больших значениях расхода топлива рекомендуется увеличение расхода воздуха в жаровую трубу за счет использования части вторичного воздуха. Но в случае, когда регулирующий орган максимально открыт, а температура газов на выходе из камеры сгорания все еще ниже расчетного значения, тогда для ее повышения возможно снижение расхода вторичного воздуха, и перепуск его, например, в одну из ступеней газовой турбины. Это позволит сохранить неизменным расход газов через турбину.

Изменение температуры газов на выходе из камеры сгорания в зависимости от изменения количества вторичного воздуха, подаваемого на выход камеры сгорания, приведено на рис.4 (вид топлива в данном случае - шахтный метан).

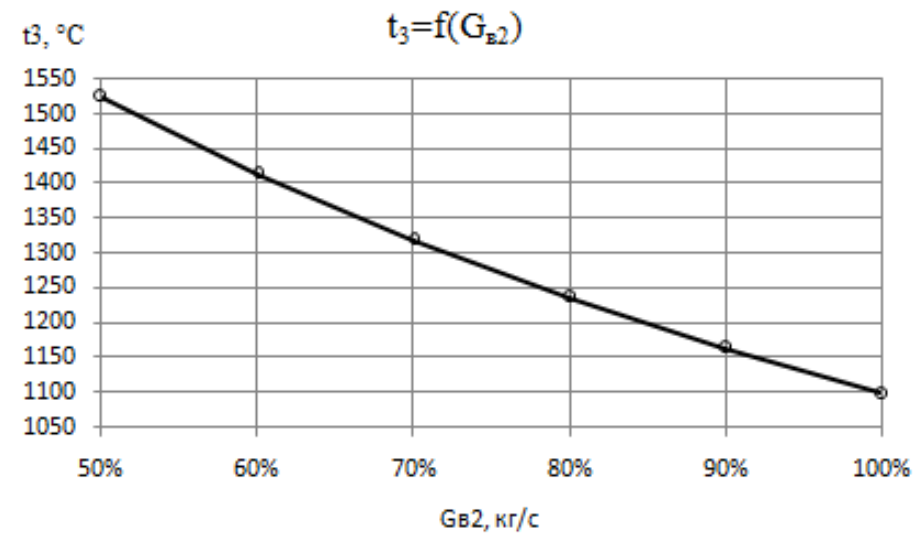

Рис. 4 - Изменение температуры газов на выходе КС в зависимости от изменения количества вторичного воздуха

Из графика, приведенного на рис. 4 видно, что снижение расхода вторичного воздуха на 50\% приводит к увеличению температуры газов на выходе КС до $1570{ }^{\circ} \mathrm{C}$. Такое значение температуры является завышенным и 


\section{МЕТОДИ ТА АЛГОРИТМИ ЕФЕКТИВНОГО УПРАВЛІННЯ ОБ‘ЭКТАМИ}

говорит о том, что изменять расход вторичного воздуха следует в меньшем диапазоне. Из графика видно, что снижение расхода вторичного воздуха на $15 \%$ достаточно для поднятия температуры газов со $1104{ }^{\circ} \mathrm{C}$ до $1200^{\circ} \mathrm{C}$.

Структурная схема стабилизации температуры газов на выходе из камеры сгорания представлена на рис. 5. Основными элементами представленной схемы являются камера сгорания (КС) в которую поступает воздух нагнетаемый компрессором (К) и топливо через регулирующий орган $\left(m_{m o n}\right)$. Турбина (Т), на ротор которой действуют движущие силы рабочего тела поступающего из КС и силы сопротивления генератора (Г) и компрессора. Воздух после компрессора нагревается в газо-воздушном подогревателе (ГВП) за счет тепла уходящих газов после турбины. Таким образом, снижается расход топлива на подогрев воздуха в камере сгорания.

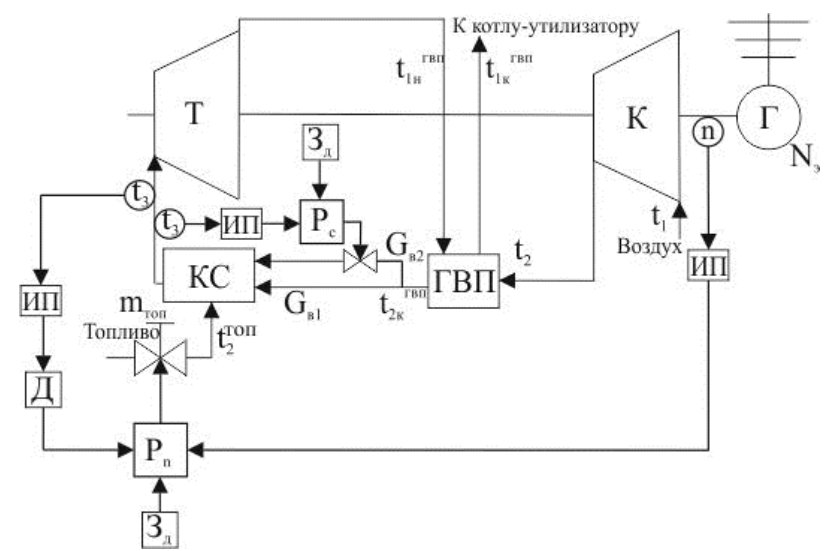

Рис. 5 - Схема стабилизации температуры газов на выходе камеры сгорания

В схеме приняты такие обозначения: $t_{1}$ - температура воздуха на входе в компрессор, ${ }^{\circ} \mathrm{C}$; $t_{2}-$ температура сжатого воздуха после компрессора, ${ }^{\circ} \mathrm{C} ; t_{2}^{m o n}-$ температура топлива, ${ }^{\circ} \mathrm{C} ; t_{3}-$ температура продуктов сгорания (газов) на выходе $\mathrm{KC},{ }^{\circ} \mathrm{C} ; t_{2 \kappa}^{2 в n}-$ температура воздуха после газо-воздушного подогревателя, ${ }^{\circ} \mathrm{C} ; t_{1 н}^{28 n}-$ температура газов на выходе из газовой турбины, ${ }^{\circ} \mathrm{C} ; t_{1 \kappa}^{\text {2вn }}-$ температура газов на выходе ГВП, ${ }^{\circ} \mathrm{C} ; P_{n}-$ регулятор частоты вращения ротора ГТУ; $3_{\partial}$ - задание; Д - реальный дифференциатор; ИП - измерительный преобразователь.

Значения расходов вторичного воздуха для всех рассматриваемых видов искусственных газов приведены в таблице 3. Порядковый номер газа в таблице 2 соответствует порядковому номеру в таблице 3.

Таблица 3. Зависимость температуры газов от расхода вторичного воздуха

\begin{tabular}{|l|l|l|l|l|l|l|l|l|l|}
\hline $\begin{array}{l}\text { Порядковый том номер } \\
\text { топлива из табл. } 2\end{array}$ & №1 & №2 & №3 & №4 & №5 & №6 & №7 & №8 & №9 \\
\hline$G_{\text {в2, кг/с }}$ & \multicolumn{7}{|l|}{${ }^{\circ}$ ' } \\
\hline $0 \%$ & 1483 & 1595 & 1875 & 2186 & 2527 & 2721 & 2764 & 2821 & 3942 \\
\hline $10 \%$ & 1317 & 1416 & 1664 & 1940 & 2243 & 2415 & 2453 & 2504 & 3499 \\
\hline $20 \%$ & 1183 & 1272 & 1496 & 1744 & 2016 & 2171 & 2205 & 2251 & 3145 \\
\hline $30 \%$ & 1075 & 1156 & 1358 & 1584 & 1831 & 1971 & 2003 & 2044 & 2856 \\
\hline $40 \%$ & 984 & 1058 & 1244 & 1451 & 1677 & 1805 & 1834 & 1872 & 2616 \\
\hline $50 \%$ & 908 & 976,3 & 1148 & 1338 & 1547 & 1665 & 1692 & 1727 & 2413 \\
\hline $60 \%$ & 843 & 906,1 & 1065 & 1242 & 1436 & 1546 & 1570 & 1603 & 2239 \\
\hline $70 \%$ & 786 & 845,2 & 993 & 1159 & 1339 & 1442 & 1465 & 1495 & 2089 \\
\hline $80 \%$ & 737 & 792 & 931 & 1086 & 1255 & 1351 & 1373 & 1401 & 1957 \\
\hline $90 \%$ & 693 & 745,1 & 876 & 1021 & 1181 & 1271 & 1291 & 1318 & 1842 \\
\hline $100 \%$ & 654 & 703,5 & 827 & 964 & 1115 & 1200 & 1219 & 1244 & 1739 \\
\hline
\end{tabular}




\section{МЕТОДИ ТА АЛГОРИТМИ ЕФЕКТИВНОГО УПРАВЛІННЯ ОБ‘ЭКТАМИ}

Результаты расчетов, приведенные в таблице 3, свидетельствуют о значительном изменении температуры газов при снижении расхода вторичного воздуха. Данные таблицы приведены для номинального значения расхода топлива $\left(G_{m o n}^{\text {ном }}=0,224\right.$ кг/с) и не учитывают увеличение расхода топлива с уменьшением температуры газов.

Логично предположить, что с увеличением расхода топлива будет уменьшаться количество вторичного воздуха, отбираемого на выходе КС с целью повышения температуры газов на входе в турбину.

Для решения поставленной задачи необходимо определить предельно возможное снижение теплотворной способности топлива, которое позволит когенерационной установке работать без снижения эффективности с учетом того, что максимальное значение расхода топлива ограничено пропускной способностью топливного клапана. Значения температуры газов на выходе КС при максимальном значении расхода топлива приведены в табл. 4.

Таблица 4. Значения температуры газов на выходе КС при максимальном расходе топлива

\begin{tabular}{|c|c|c|c|c|c|c|c|c|c|}
\hline $\begin{array}{l}\text { Порядковый } \\
\text { топлива из табл. } 2\end{array}$ & №1 & №2 & №3 & №4 & №5 & №6 & №7 & №8 & №9 \\
\hline$G_{\text {в2}}$, кг/с & \multicolumn{9}{|l|}{$t_{3},{ }^{\circ} \mathrm{C}$} \\
\hline $0 \%$ & 1572 & 1706 & 2041 & 2415 & 2824 & 3057 & 3109 & 3178 & 4522 \\
\hline $10 \%$ & 1395 & 1514 & 1812 & 2144 & 2507 & 2713 & 2759 & 2820 & 4013 \\
\hline $20 \%$ & 1254 & 1361 & 1629 & 1927 & 2253 & 2439 & 2480 & 2535 & 3608 \\
\hline $30 \%$ & 1139 & 1236 & 1479 & 1750 & 2046 & 2215 & 2253 & 2302 & 3276 \\
\hline $40 \%$ & 1043 & 1132 & 1355 & 1603 & 1874 & 2028 & 2063 & 2109 & 3001 \\
\hline $50 \%$ & 962 & 1044 & 1250 & 1478 & 1729 & 1871 & 1903 & 1945 & 2768 \\
\hline $60 \%$ & 893 & 969 & 1160 & 1372 & 1604 & 1736 & 1766 & 1805 & 2569 \\
\hline $70 \%$ & 833 & 903,9 & 1082 & 1280 & 1497 & 1620 & 1648 & 1684 & 2396 \\
\hline $80 \%$ & 781 & 847 & 1014 & 1199 & 1403 & 1518 & 1544 & 1578 & 2246 \\
\hline $90 \%$ & 734 & 796,9 & 954 & 1128 & 1320 & 1428 & 1452 & 1484 & 2113 \\
\hline $100 \%$ & 693 & 752,3 & 900 & 1065 & 1246 & 1348 & 1371 & 1401 & 1995 \\
\hline
\end{tabular}

\section{Выводы}

Теоретически для рассматриваемой когенерационной установки в качестве топлива можно использовать все рассмотренные газы искусственного происхождения. Диапазон изменения теплотворной способности топлива при этом составляет от 11941 кДж/кг до 78322 кДж/кг.

Для топлив с теплотворной способностью ниже 30981 кДж/кг эксплуатация КЭУ будет происходить на расходах топлива близких к максимальным. Это говорит о том, что для этих топлив поддержание температуры в заданных пределах возможно только за счет перераспределения потока вторичного воздуха. Такой вариант регулирования может иметь невысокую надежность и точность, т.к. отсутствует возможность для маневрирования при увеличении электрической нагрузки.

Таким образом, можно выделить пределы снижения теплотворной способности топлива, позволяющие эксплуатацию когенерационной установки без снижения эффективности. Таким пределом является значение теплотворной способности 30981 кДж/кг.

\section{Литература}

[1] Рябцев, Н.И. Природные и искусственные газы // М.: Стройиздат, 1967. - 328 с.;

[2] Ольховский, Г.Г. Разработка отечественной ПГУ с газификацией угля // Теплоэнергетика. - 2010. -

№2. - C. $19-26$;

[3] Розенгарт, Ю.И. Вторичные энергетические ресурсы черной металлургии и их использование // К. : «Высш. шк.», 2008. - 328 с.;

[4] Ярошевский, С.Л. Эффективность и перспективы замены природного газа пылеугольным топливом в доменных цехах Украины // Металл и литье Украины. - 2010. — № 7. - С. 13 - 20.;

[5] Бондаренко, А.В. Повышение эффективности горения углеводородных газов в парогенерирующих установках за счет изменения отношения топливо/воздух: дис. ... канд. техн. наук // А.В. Бондаренко. - Одесса., 2014. 174 c.;

[6] Костюк, А.Г. Паровые и газовые турбины для электростанций // М.: Издательский дом МЭИ, 2008. - 556 С.; 


\section{МЕТОДИ ТА АЛГОРИТМИ ЕФЕКТИВНОГО УПРАВЛІННЯ ОБ‘ЭКТАМИ}

[7] Бундюк А.Н., Тарахтий О.С. О повышении качества управления мощностью ГТУ когенерационной энергетической установки // І всеукраїнська наук.-техн. конф. «Автоматизація, контроль та управління: пошук ідей та рішень». - 2015. - 25 -29 трав. м. Красноармійськ. - С. $444-447$;

[8] Пчелкин, Ю.М. Камеры сгорания газотурбинных двигателей : учеб. / Ю.М. Пчелкин. - 3-е изд., перераб. - М. : Машиностроение, 1984. - 280 с.

\section{References}

[1] Ryabcev N.I. Natural and artificial gases / of N.I. Ryabcev - M. of Stroyizdat, 1967 -328.;

[2] Ol'khovskii G.G. The development of the domestic PSU with gasification of coal // Thermal Engineering. -2010. №2. - P. $19-26$;

[3] Rozengart YU. I. Secondary power resources in ferrous metallurgy and their use / of YU. I. Rozengart -K. of High school, 2008 - 328.;

[4] Yaroshevskii S.L. The effectiveness and prospects of replacement of natural gas with pulverized-coal fuel into the blast furnace shops of Ukraine // Metal and casting of Ukraine. - 2010. - № 7. - P. 13 - 20.;

[5] Bondarenko A.V. Improving the efficiency of combustion of hydrocarbon gases in steam generating units by changing the fuel/air: diss. candidate of technical Sciences // A.V. Bondarenko. - Odessa. - 2014. - 174.;

[6] Kostyuk A.G. Steam and gas turbines for power plants // M. of Publishing house of MEI, 2008. - 556.;

[7] Bundiuk A.N., Tarakhtii O.S. About improving the quality management capacity of the gas turbine cogeneration power plant // "Automation, control and management: the search for ideas and solutions". - Krasnoarmeysk. - 2015.;

[8] Pchelkin YU.M. Combustion chamber for gas turbine engines: tutorial. - M. of Mechanical, 1984. - 280.

\section{[9] AUTOMATION NEWS}

\section{Industry Adapting to Collaborative Robots}

In this exclusive interview with Yaskawa's Chetan Kapoor, he explains how industry's evolving mindset toward production, metrics and business models are paving the way for greater use of robots working alongside humans on the production line. One of the first media properties I worked for back in the early 1990s was "Robotics World." As a staff editors on that publication at the time, We often heard how we had missed the glory days of the robotics industry back in the early to mid 1980s when U.S. industrial adoption of robots was at its peak. By the early 1990s, most experts thought U.S. industry was satiated with robots and no more large-scale implementations would be happening any time soon.

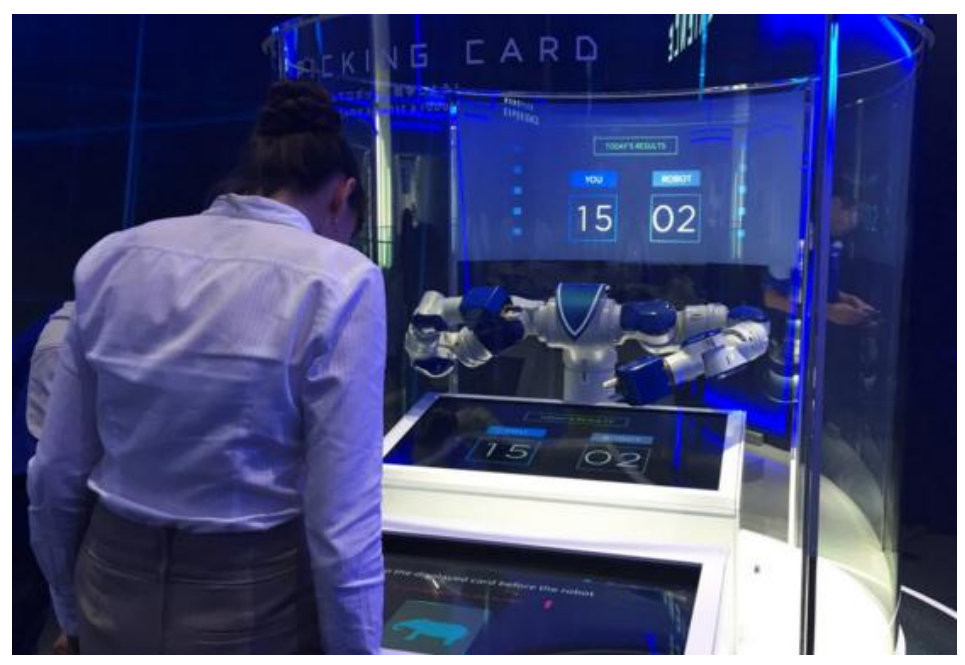

Though things were quiet on the industrial robotics front for many years after that, robotics technology kept advancing. Now, with the emergence of collaborative robots, we seem to be on the cusp of a new age of robotic deployment that could well surpass the heady days of robot deployment in the 1980s. Kapoor will participate in the Collaborative Robotics panel at The Automation Conference and Expo 2016 to be held May 24-25 in Chicago. For more information and to register, visit: www.theautomationconference.com.

http://www.automationworld.com 